\title{
Speed Control of Seperately Excited DC motor for Electric Vehicles (EVs) By Inverse Model Based Fuzzy Learning Controller
}

This paper was downloaded from TechRxiv (https://www.techrxiv.org).

\section{LICENSE}

CC BY-NC-SA 4.0

SUBMISSION DATE / POSTED DATE

$11-10-2021 / 14-10-2021$

\section{CITATION}

bulut, mehmet (2021): Speed Control of Seperately Excited DC motor for Electric Vehicles (EVs) By Inverse Model Based Fuzzy Learning Controller. TechRxiv. Preprint. https://doi.org/10.36227/techrxiv.16783258.v1

$\mathrm{DOI}$ 


\title{
Speed Control of Seperately Excited DC motor for Electric Vehicles (EVs) By Inverse Model Based Fuzzy Learning Controller
}

\author{
Mehmet BULUT ${ }^{1,2}$ \\ ${ }^{1}$ Electricity Generation Co. Inc., General Management, 06830 Ankara, Turkey \\ ${ }^{2}$ Atilim University, School of Civil Aviation, Ankara, TURKEY \\ mehmetbulut06@gmail.com, Orcid: 0000-0003-3998-1785
}

\section{H I G H L I GH T S}

- Fuzzy model reference based learning approach

- Obtaining the fuzzy controller rule base from system model behaviors

- Applicability for dc motor speed control of EVS

- Adjustment fuzzy controller using fuzzy inverse model

\begin{abstract}
The adaptation mechanism, which adjusts the controller coefficients according to the parameter changes in the system, ensures that the controller is adaptable. Fuzzy logic can be used to calculate the gain coefficients of the controller in the system by using the adaptive fuzzy method instead of a traditional algorithm for the adaptation mechanism. Normally, the rules of a fuzzy controller system are derived from the system's internal structure and system behavior using expert knowledge that has experienced the system. However, it is not possible to derive fuzzy rules based on expert human knowledge for all systems in this way. It is necessary to use different methods to derive fuzzy rules in highly variable behavior and nonlinear systems. In this study, an adaptive fuzzy controller design for dc motor was made using a learning-based reference model learning algorithm using fuzzy inverse model; It has been shown that it is applicable for dc motors with the results obtained. Simulation of the designed system was carried out using the Matlab program, and the behavior of the system was investigated by using constant and variable loads. The results showed that it is satisfactory to drive a dc motor with adaptive fuzzy controller in terms of system stability.
\end{abstract}

Keywords: Fuzzy control, Reference model, DC Motor, Adaptive controller, Electric Vehicles

\section{INTRODUCTION}

Fuzzy control has emerged as alternative control method to several conventional controls since it has shown success in some application areas; however, there are several drawbacks to this approach: the design of fuzzy controllers is usually performed in a heuristic manner where it is often difficult to choose some of the controller parameters, e.g., the membership functions. The adaptive fuzzy method can be used for the adaptation mechanism that adjusts the controls according to the parameter changes in the system. Normally, the fuzzy rules of the system are derived from the internal structure and behavior of the system. However, it is not possible to extract fuzzy rules based on expert human knowledge in this way for all systems. There is a need for different methods for the extraction of fuzzy rules in nonlinear systems with highly variable behavior. In some fuzzy control applications is very difficult to specify the rule base for some plants, or the need could arise to tune the rule-base parameters if the plant changes. This provides the motivation for adaptive fuzzy control, where the focus is on the automatic on-line synthesis and tuning of fuzzy controller parameters, i.e. the use of on-line data to continually "learn" the fuzzy controller, which will ensure that the performance objectives are met.

DC motors are preferred for speed control in electric vehicles as they are used in many industrial areas today. Speed control can be used to cope with variable operating conditions i.e. load distortion, parameter uncertainty, measurement noise, etc. is a common requirement in industrial drives [1]. Conventional 
Bulut M., (2021)

controllers with fixed parameters are not very successful in real-time applications due to deviations in process operating conditions. Adaptive controller techniques are best suited for these situations. As with sudden large load changes and inertia changes in motors, constant parameter controllers are not sufficient to control many systems [2]. In these cases, more complex controls need to be used. For example, adaptive controllers have the ability to change their properties to maintain the desired dynamic behavior of the system when there is a parameter change in the system. Recently, different adaptive controller algorithms have been theoretically developed and tested in some applications. However, very few of them can be used to control them due to the complexity or poor performance of electrical drives. The model reference adaptive controller approach requires less computation time compared to self-tuning and other adaptive controller techniques, and they generally show a better fit in terms of performance and complexity.

Shahgholian et al., in their study, compared the performance of a conventional model reference adaptive control and a model reference fuzzy adaptive control [3]. Layne and Passino examined the use of a fuzzy logic-based adaptive supervisory learning system to maintain adequate performance of a cargo ship autopilot when there are process disruptions or variations [4][5]. Sheel et al., on the other hand, demonstrated the performance of the dc driver in speed control by using a conventional model reference adaptive controller. They found that the fluctuation in the load causes gradual disturbance in the process, which in turn causes deviation from the desired speed [6]. Farahani and Rahmani, on the other hand, proposed a new fuzzy nerve (FN) controller to control the speed of a separately excited DC motor [7]. Typically, a fuzzy system is used for a "fuzzy controller" to use a human expert's knowledge of how to control the process for use in a computer algorithm. The expert's knowledge and experience about the system is used as a preliminary knowledge for fuzzy controls. Expert knowledge is required to determine the rules to be used in a normal fuzzy controller. In the adaptive fuzzy controller, there are studies in which one or more of the artificial intelligence methods such as neural networks and evolutionary algorithms are used together to automatically derive the necessary fuzzy rules from the system data [8],[9]. Fuzzy controllers based on fuzzy logic and fuzzy rules are widely used in many applications today [10],[11]. Despite the well-known advantages of fuzzy logic-based controllers, the development of a specific system for them is still by trial and error, due to the lack of an analytical design method. However, there are self-learning procedures with artificial neural networks and similar methods, and it is possible to overcome such an obstacle. The algorithm of the fuzzy logic-based model reference adaptive controller, on the other hand, uses a reference model that shows how the system behaves instead of expert human knowledge, which provides the basic information of the fuzzy controller, which increases the closed-loop feedback performance that provides the fundamental information exchanges. In addition, there are different methods used in the literature to automatically arrange fuzzy rules [12], [13]. Fuzzy model reference controller algorithm can be used in systems that do not have enough information about their behavior or that vary widely [14]. Studies for Angular Speed Control of DC Motor and including Neuro Adaptive approaches have also been done [15], [16].

In the study, an adaptive fuzzy controller design that realizes the speed control of the direct current (DC) motor was made by using a learning-based fuzzy model reference learning controller algorithm. Here, the learning control algorithm is directly based on a fuzzy controller. In the study, general information about the fuzzy model reference learning controller was given, and it was revealed that the results of the application were successful. The parts that make up the system are examined separately and the rulebased learning mechanism is examined in detail. In the adaptive fuzzy control using the dc motor model selected in this study: a) the reciprocal increase of the defined reference model speed of the system and the motor speed, b) the reduction of the noises in the system response under load changes and interruptions, and c) the increase of the system stability. Mentioned method has used for a electrical vehicle speed control and results is denoted. In electric vehicles, it is found as a result of the sum of the resistance forces that the electric motor that drives the vehicle must overcome in motion with the net force required to move the vehicle. The rotational speed and torque values of the electric motor providing the traction force are widely used in electric vehicle modeling. The designed system was simulated using the Matlab program, and the behavior of the system was examined using constant and variable loads. The obtained results showed that satisfactory results were obtained with fuzzy adaptive control in terms of system stability. 


\section{MATERIAL AND METHODS}

\subsection{EV's Speed Control Model}

The electric motor model is the part of the electric vehicle system where the transition from mechanical design to electrical design is achieved. Separately excited dc motor is one of the commonly used dc motor types in many applications. Its distinctive feature is the excitation winding and the armature winding consists of two power sources, respectively, and has parameters that can be controlled more effectively. They are also applied to main drive systems and electric cars, as they have a wide speed range and efficient features. In addition, after the motor starts, its control can be achieved by reducing the armature voltage. In the process of speed regulation, respectively armature, excitation control, motor can make smooth and constant speed. The methods used for fast braking in separately excited DC motor applications are energy consumption braking, reverse connection braking is used. It is possible to provide rapid braking when the motor is de-energized from the power supply [17].

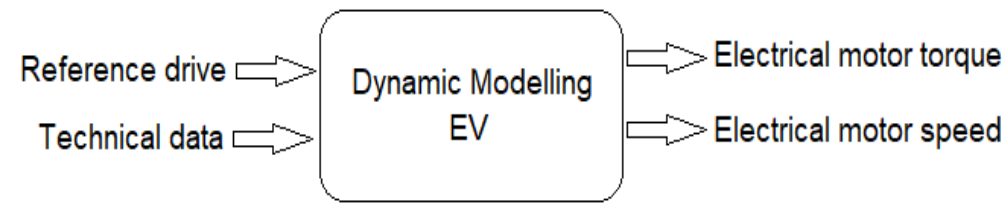

Figure 1. Electric vehicle (EV) Dynamic modeling inputs and outputs

The separately excited synchronous motor structure is a topology provided by the windings on the rotor. The magnetic field needed to produce torque is produced by the rotor coils. The rotor winding in this type of motor has a similar function to the permanent magnets of PM motors. Figure 2 shows an electric vehicle diagram using the excited synchronous motor structure.

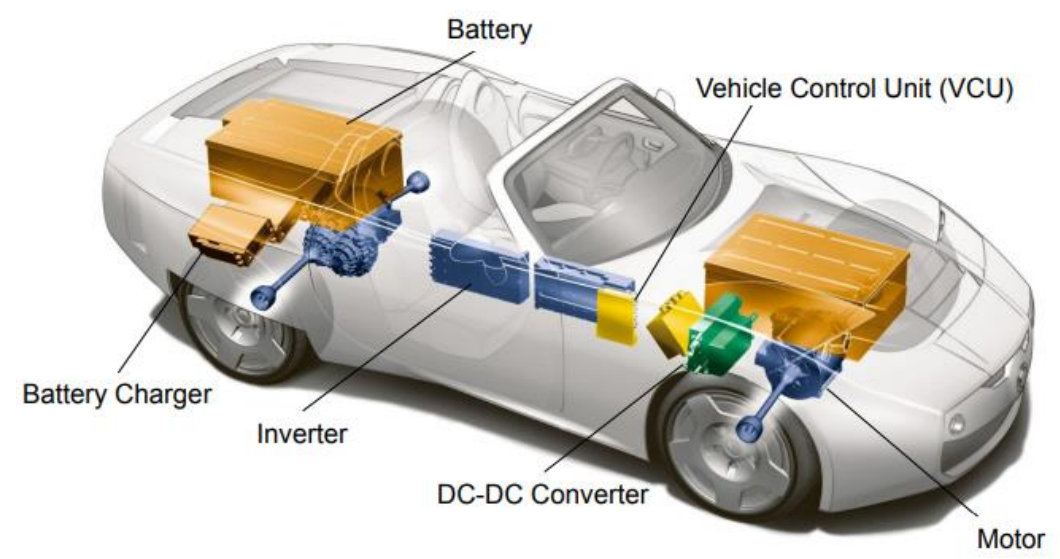

Figure 2. Electric vehicle (EV) Dynamic modeling inputs and outputs [18]

\subsection{Fuzzy Model Reference Learning Control}

In this study, the derivation and adjustment of the dc motor speed at the desired reference values was carried out by combining fuzzy logic and traditional adaptive model controller. The model reference and fuzzy controller are designed based on maintaining the overall system stability. A fuzzy adaptation method has been used instead of a traditional algorithm such as the adaptation mechanism that adjusts the coefficients of the controller according to the parameter changes in the system to be controlled. In other words, the fuzzy logic rules to be used for calculating the gain coefficients of the controller are extracted with a learning algorithm. In traditional applications, fuzzy rules are derived from the internal structure and behavior of the system. However, it is not possible to define or extract fuzzy rules in this way for all systems. Learning-based methods are preferred for the extraction of fuzzy rules in systems with highly variable behavior. In this study, a reference model-based fuzzy learning algorithm was preferred. It is shown in Fig.3, utilizes a learning mechanism that observes data from a fuzzy control system, characterizes its current performance, and automatically adjusts the knowledge base of the fuzzy controller so that the closed-lop system performans according to the specifications given by the reference 
Bulut M., (2021)

model . There are four components in this system: the plant, reference model, fuzzy controller that will be tuned, and fuzzy inverse model [19].

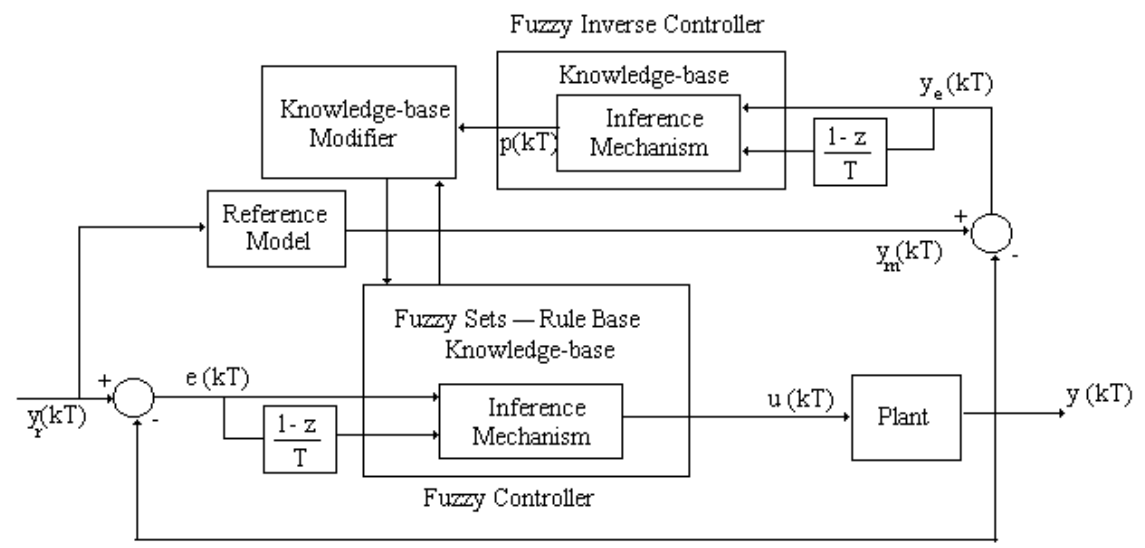

Figure 3. Fuzzy Model Reference Learning Control Structure

\subsection{The Fuzzy Controller}

Fuzzy controller initially knows nothing about how to control the plant. As the algorithm executes, the output fuzzy sets are rearranged by the learning mechanism, fill-in up the rule-base. For instance, once a slew is commanded the learning mechanism described below will move the centers of the activated rules away from zero and begin to synthesize the fuzzy controller. The fuzzy controller here has two inputs and one output. One input is the error (e) and the other is the change in error (c). The input of the fuzzy controller is defined as a function of the dc motor speed information $y(k T)$ used as the process and the reference input value $\mathrm{yr}(\mathrm{kT})$ indicating the desired speed. Fuzzy controller inputs error signal e(kT) $=[\mathrm{e} 1(\mathrm{kT}), \ldots \ldots \ldots \ldots . ., \mathrm{es}(\mathrm{kT})] \mathrm{T}$ and change in error signal $\mathrm{c}(\mathrm{kT})=[\mathrm{c} 1(\mathrm{kT})$, , cs(kT)]T is defined as in Fig 3.,

$$
\begin{aligned}
& e(k T)=y_{r}(k T)-y(k T) \\
& c(k T)=\frac{e(k T)-e(k T-T)}{T}
\end{aligned}
$$

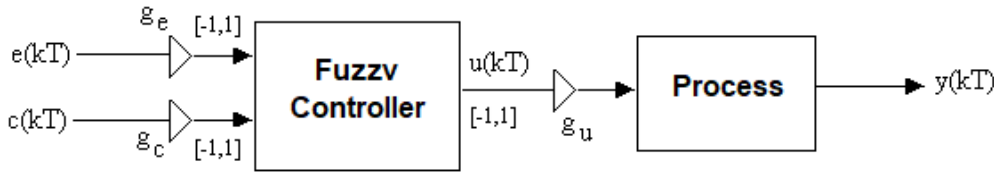

Figure 4. Parameter ranges used in fuzzy controller inputs and outputs.

The fuzzy controller uses 11 uniformly distributed triangular membership functions for each of its input universes of discourse. It uses triangular shaped output membership functions that shown in Fig.5. The fuzzy controller uses minimum to represent the premise and implication, and the center of gravity (COG) defuzzification. 
Bulut M., (2021)

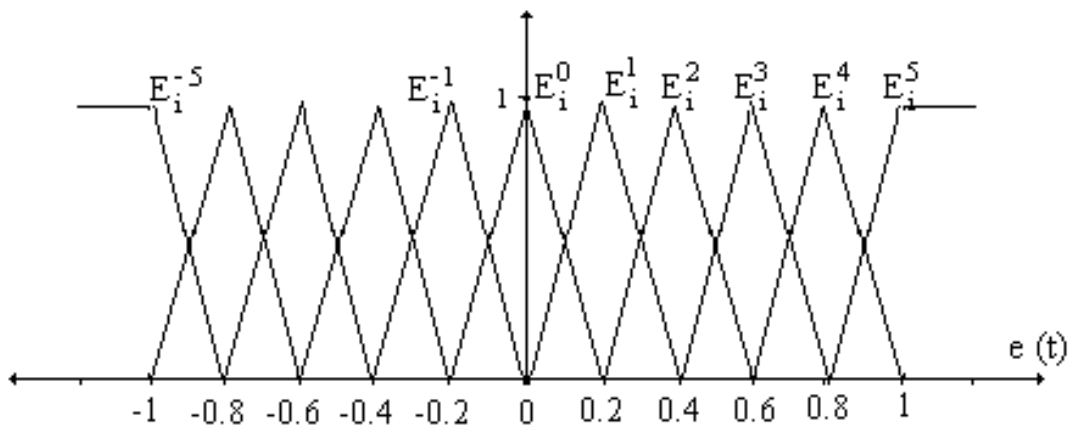

Figure 5. Triangular membership functions for each of input and output for fuzzy controller.

The output membership function $\mu(x)$ centers of the fuzzy controller are what is tuned by the learning mechanism of the fuzzy model reference learning control system. The membership function is used to calculate the membership degree in fuzzy sets where the controller input and output parameters coincide in the rule.

$$
\mu_{E^{i}}(x)=\left\{\begin{array}{lll}
\max \left(\left[0,1+\frac{\mathrm{x}-\mathrm{c}_{\mathrm{E}^{\mathrm{i}}}}{\mathrm{w}}\right]\right), & \mathrm{x}<=\mathrm{c}_{\mathrm{E}^{\mathrm{i}}} & \mathrm{i}=1 \ldots 11 \\
\max \left(\left[0,1+\frac{\mathrm{c}_{\mathrm{E}^{\mathrm{i}}}-x}{\mathrm{w}}\right]\right), & \mathrm{x}>\mathrm{c}_{\mathrm{E}^{\mathrm{i}}} & \mathrm{i}=1 \ldots 11
\end{array}\right.
$$

In here, $\mathrm{C}_{\mathrm{E}}$ is center of membership function and $w$ is witdh of membersip function.

\subsection{The Reference Model}

The reference model is a model of how we would like the closed-loop system to behave. The reference model may be any type of dynamical system either linear or nonlinear. It is used to characterize closedloop specifications such as rise-time, overshoot, and settling time. The performance of the overall system is computed with respect to the reference model by generating error signals between the reference model output and the plant outputs To achieve the desired performance the learning mechanism must force $\left.\mathrm{y}_{\mathrm{e}}(k T) \approx 0\right)$; 0 for all $\mathrm{k}>0$.

\subsection{The Learning Mechanism}

The learning mechanism performs the function of modifying the knowledge base of the fuzzy controller so that the closed-loop system behaves like the reference model. The learning mechanism consists of two parts: the fuzzy inverse model and the knowledge-base modifier. Thus, the fuzzy controller controlling the system will be learned from the system behaviors. Initially, the fuzzy controller does not know how to control the process, so the matrix representing the rule base is empty.

\subsubsection{The Fuzzy Inverse Model}

The fuzzy inverse model acts as a controller in the adaptation loop to try to reduce the deviation in the closed-loop system behavior from the desired behavior by changing the underlying fuzzy controller. Essentially, the fuzzy inverse model constructs the fuzzy controller via the knowledge-base modifier using on-line data from the closed-loop system so that the behavior specified in the reference model is achieved.. Fuzzy model reference learning control structure uses similar a priori knowledge to that used in the off-line design of conventional fixed direct fuzzy controllers, to decide how to adjust the direct fuzzy controller. Rule base of fuzzy inverse model in this paper is shown Fig. 6. 
Bulut M., (2021)
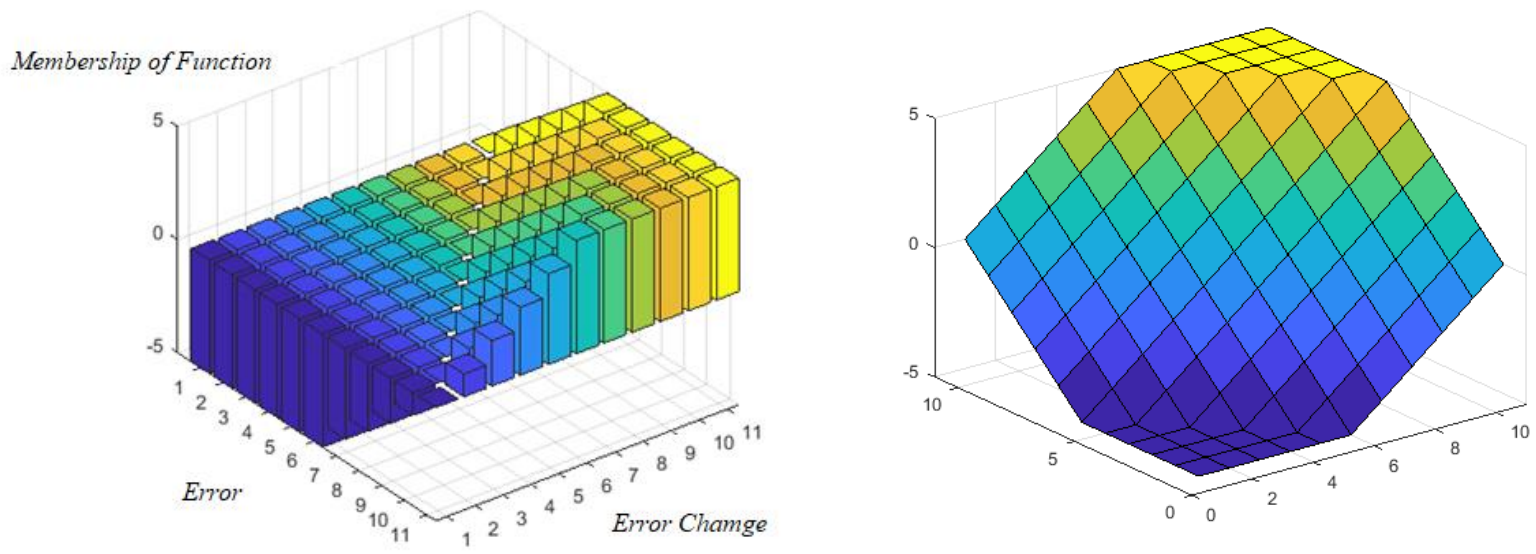

Figure 6. Rule-base for fuzzy inverse model and rule-base mapping

\subsubsection{The Knowledge-Base Modifier}

The knowledge-base modifier performs the function of modifying the fuzzy controller so that better performance is achieved. Given the information (from the inverse models) about the necessary changes in the input needed to make $y_{\mathrm{e}} \approx 0$, the knowledge-base modifier changes the knowledge-base of the fuzzy controller so that the previously applied control action will be modified by the amount specified by the inverse model outputs $p(k T)$.

\section{DC MOTOR SYSTEM EQUATIONS}

A direct current motor has two basic components, the field windings and the armature windings invariably mounted on the rotor. These two sets of windings have their axes mounted electrical space quadrature, and both supplied with power from direct current electrical sources. Dc motor drives is highly controllable and are used in many industrial applications such as robotic manipulators, position control, steel, mining, paper, textile industries and electric vehicles.

The injection of direct current through the field windings establishes an excitation current which sets up a field of flux the motor air gap [5]. In therms of intantaneous variables are,

$$
\begin{array}{ll}
v_{a}=R_{a} \cdot I_{a}+L_{a} \cdot \frac{d I_{a}}{d t}+E_{b} & E_{b}=K_{b} \cdot w_{m} \\
T=J \cdot w_{m}+B \cdot \frac{d w_{m}}{d t}+T_{L} & T=K_{i} \cdot I_{a}
\end{array}
$$

$T_{e}=K_{b} i_{a}$

$T_{a}=T_{e}-T_{L}$

Where, $w_{m}(t)$ is motor speed $(\mathrm{rad} / \mathrm{s}), I_{a}(t)$ armature current (A), $v_{a}$ is dc supply voltage (constant), La armature inductance, $R_{a}$ armature resistance, $E_{b}$ back emf , $T_{L}$ load torque, $T_{e}$ is electromechanical torque (air gap), $T_{a}$ acceleration torque, $J$ inertia torque and $B$ is friction coefficient.

The state-space equations of seperately excited dc motor under above equations is as follows:

$$
\begin{aligned}
& \dot{x}=A^{*} x+B^{*} u \\
& y=C^{*} x+D^{*} u
\end{aligned}
$$


Bulut M., (2021)

$$
\begin{aligned}
A & =\left[\begin{array}{cc}
-\frac{B}{J} & \frac{K_{i}}{J} \\
\frac{K_{b}}{L_{a}} & -\frac{R_{a}}{I_{a}}
\end{array}\right], \quad B=\left[\begin{array}{cc}
0 & \frac{-1}{J} \\
\frac{1}{L_{a}} & 0
\end{array}\right], \quad C=\left[\begin{array}{ll}
1 & 0
\end{array}\right], \quad D=\left[\begin{array}{ll}
0 & 0
\end{array}\right] \\
x & =\left[\begin{array}{ll}
w_{m}(t) & I_{a}(t)
\end{array}\right]^{T} \\
y & =\left[\begin{array}{ll}
w_{m}(t)
\end{array}\right] \\
u & =\left[\begin{array}{ll}
v_{a} & T_{L}
\end{array}\right]^{T}
\end{aligned}
$$

In case of load torque $\left(T_{L}\right)$ equal to zero then motor transfer function is below as $v_{a}(s)$ is input and $W(s)$ is output,

$$
G(s)=\frac{w_{m}(s)}{v_{a}(s)}=\frac{K_{i}}{s^{2} J \cdot L_{a}+s\left(B \cdot L_{a}+J \cdot R_{a}\right)+B \cdot R_{a}+K_{b} \cdot K_{i}}
$$

If there is load torque $\left(T_{\mathrm{L}}\right)$ connected to the motor, the motor output speed is equal to $w_{m}(\mathrm{~s})$.

$$
w_{m}(s)=\frac{K_{i}}{s^{2} J \cdot L_{a}+s\left(B \cdot L_{a}+J \cdot R_{a}\right)+B \cdot R_{a}+K_{b} \cdot K_{i}} v_{a}(s)+\frac{R_{a}+s L_{a}}{\left(R_{a}+s L_{a}\right) \cdot(J+s B)+K_{b} \cdot K_{i}} T_{L}
$$

In this paper used dc motor parameters for plant are ;

Moment of inertia of the rotor $(\mathrm{J}) \quad: 0.01 \mathrm{~kg} \cdot \mathrm{m}^{2}$

Motor viscous friction constant $(B) \quad: 0.1 \mathrm{Nms}$

Armature resistance $(\mathrm{Ra}) \quad: 1.0 \mathrm{ohm}$

Armature inductance (La) $\quad: 0.5 \mathrm{H}$

(Ke) Electromotive force constant $: 0.01 \mathrm{~V} / \mathrm{rad} / \mathrm{sec}$

(Kt) Motor torque constant :0.01 N.m/Amp

As reference model can be considered as the representation of the essential parts of the system in a convenient form. The simpliest and most useful method of representing the behaviour of a system is by a mathematical model. The goal of the FMRLC is to make the closed-loop system behave like a given reference model. Here, our reference model is a first order system that represents how we would like the system. Through this experimentation we determined that

$$
G_{m}(\mathrm{~s})=\frac{1}{S+1}
$$

is a good choice for the reference model for dc motor.

\section{RESULTS AND DISCUSSION}

Digital simulation studies for model based learning fuzzy controller validition the on-line model based control structure were performed for following case: Motor starts under no-load for unit step in reference speed. Learning as wieved as the estimation or successive approximation of the unknown quantities of a function. As the learning algorithm executes, the output fuzzy sets are rearranged by the learning mechanism. After learning, rule base of fuzzy controller fill-in up values which show center of memebership functions. Constructed rule-base mapping after learning for fuzzy controller is shown in figure 6. In case changes occured in parameters of system, model based learning fuzzy controller started execute by learning again and learn new rule-base, it use this for controlling system. 
Bulut M., (2021)

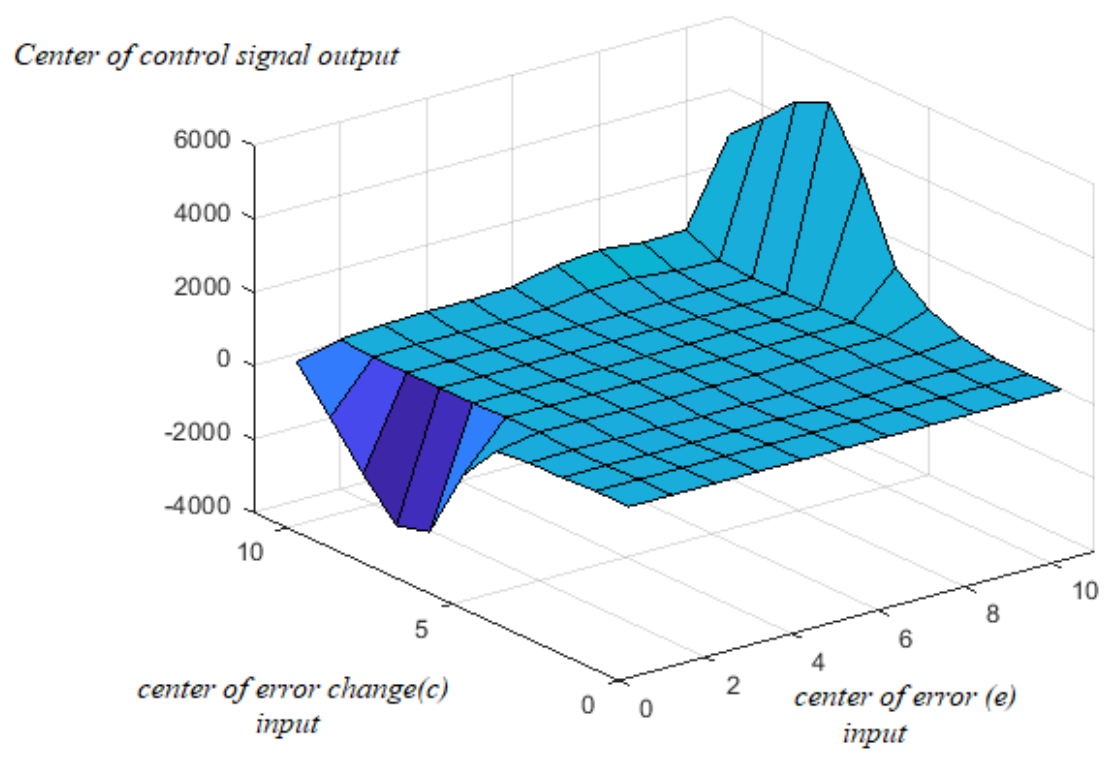

Figure 6. Constructed rule-base mapping after learning for fuzzy controller

The changes of the error and error change inputs in the proposed model-based learning fuzzy control system corresponding to the given reference vehicle speed scenario are shown in Figure 7.
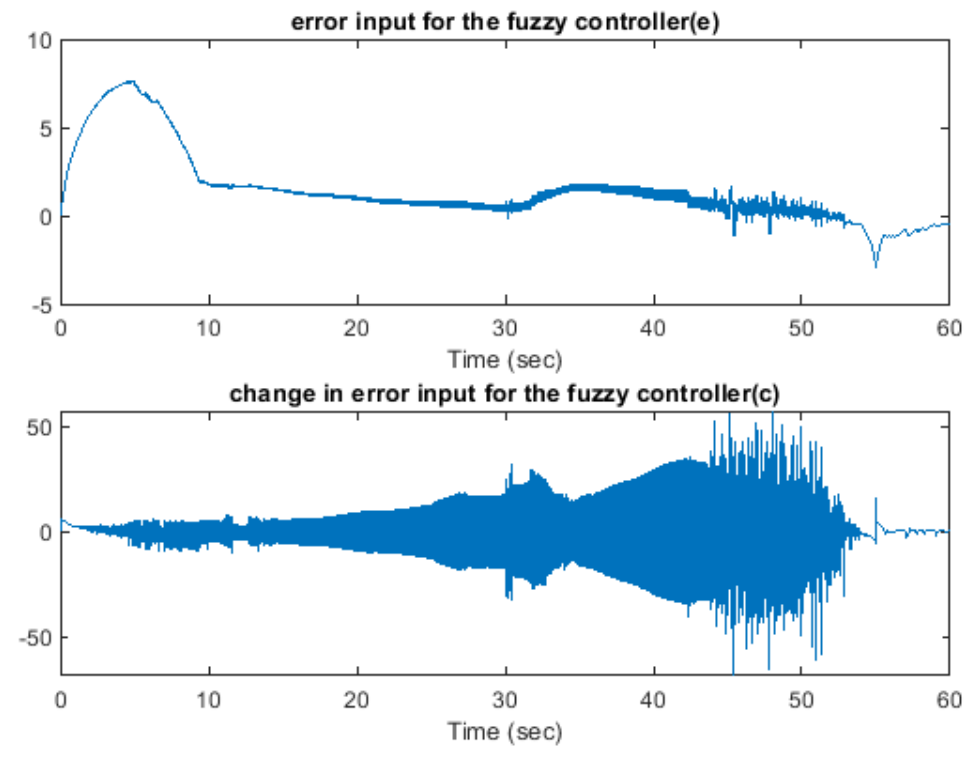

Figure 7. The changes of the error and error change inputs in the proposed model-based learning fuzzy control system 
Bulut M., (2021)
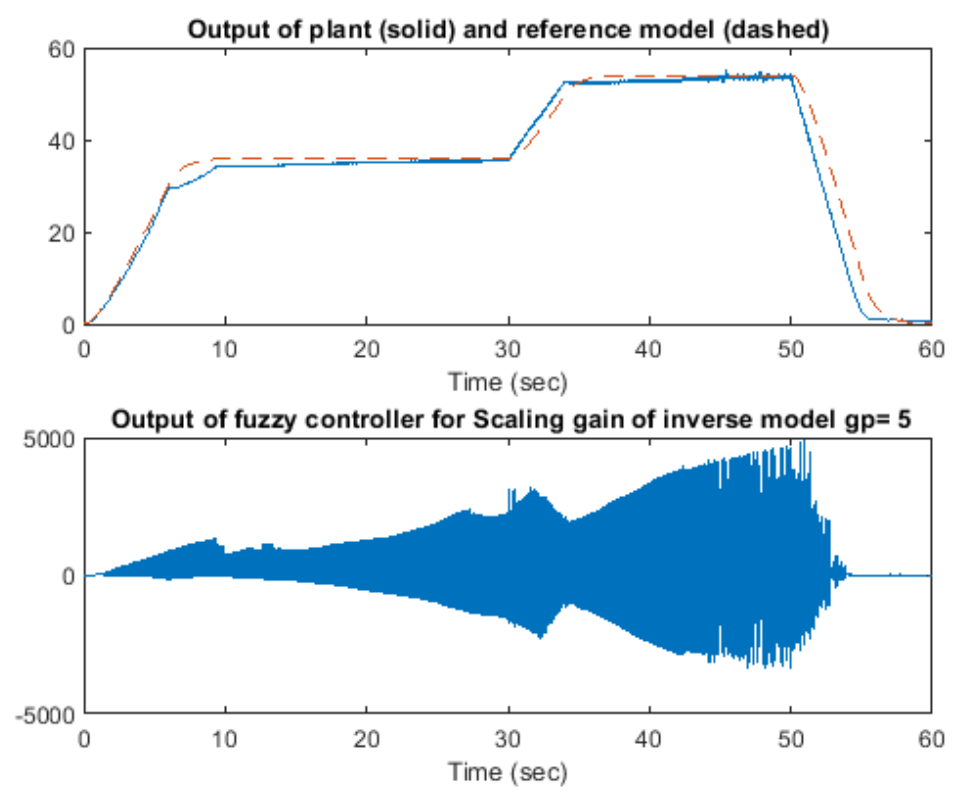

(a)

(b)

Fig 8. During learning a) plant output and model output b) Fuzzy controller output scalling values to plant inverse model.

During learning fuzzy controller for dc motor via model plant and model outputs and constructed fuzzy controller output is shown fig. 8. The 3D map of the Fuzzy controller rule base after learning is also shown in Figure 6. During the learning through the model system for the DC motor, the model output and the configured fuzzy controller output are shown in Figure 7-8.

As can be seen from the results in Figure 8, the system output reached the reference speed in less than 5 seconds with the rule-based fuzzy control designed using this method. The results obtained by applying the fuzzy controller obtained after the learning phase with the model-based fuzzy learning algorithm to the DC motor at various reference values are given in Figure 9-10.
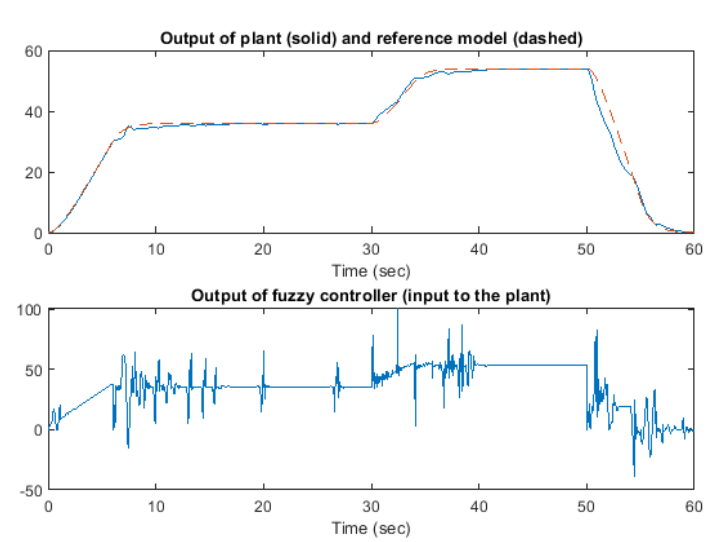
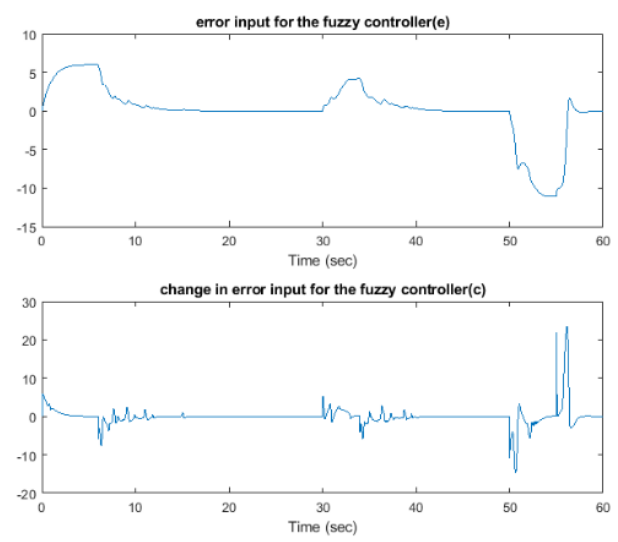

Fig 9. For plant scenario-1 a) output of plant and fuzzy controller output signals b) Fuzzy controller input signals 
Bulut M., (2021)
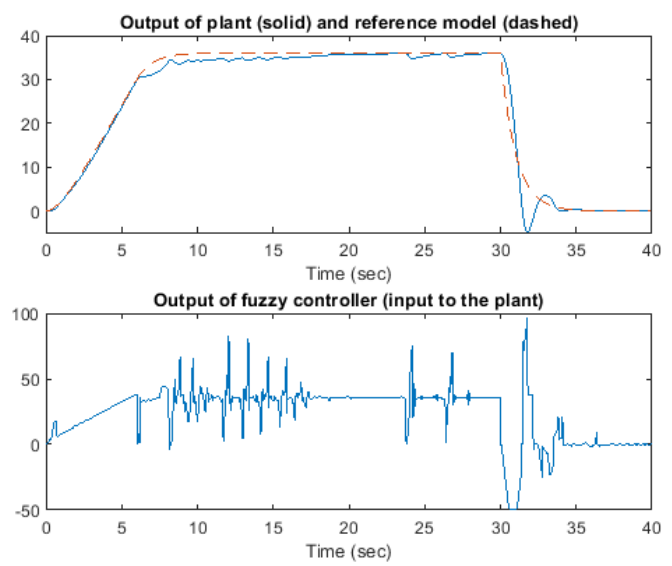
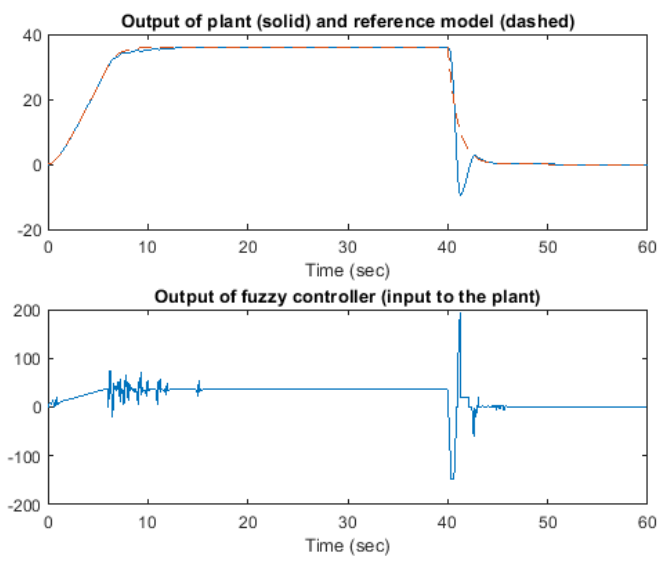

Figure 10. For reference model output of plant and fuzzy controller output signal a) scenario-2 b) scenario-3

Since developing a properly organized fuzzy rule base without the help of human expert knowledge is a challenging process, it takes a long time to develop a fuzzy controller rule base suitable for a given system. In this study, an adaptive fuzzy controller is used instead of traditional algorithms in the speed control system of a dc motor over a model reference algorithm. Such an adaptive fuzzy controller is based on an appropriate set of fuzzy rules derived from knowledge on the internal structure of the controlled system and the behavior of the system. Whereas, the fuzzy model reference learning controller algorithm provides a method based on automatic learning to directly design the fuzzy controller knowledge base and organize it against new situations. A fuzzy controller can perform well in controlling any system, but it is not sufficient in case of unpredictable system parameter changes or any load changes. Because the designed rule base must include all possible situations in order to be successful.

\section{CONCLUSION}

In this study, it is aimed to control the speed of a dc motor by using a fuzzy adaptive controller learning algorithm including an inverse fuzzy controller for electrical vehicle speed control application. Accordingly, adaptive fuzzy speed control for the dc motor will be made based on the use of fuzzy set laws for the adaptive process. In order to use fuzzy logic in the control of a dc motor, a fuzzy system whose parameters are determined by the learning algorithm and which can adapt itself to system changes should be developed so that it can quickly and steadily set the dc motor speed to the desired reference value in unloaded or loaded situations. Here, it has been studied by automatically learning the rule base to the fuzzy controller for direct current motor speed control for electric vehicles based on fuzzy logic. Therefore, for this purpose, the learning algorithm has been analyzed and used for the DC motor control system. Tuning the rule-base requires experience with long time. Proposed fuzzy model based learning controller for dc motor application of electrical vehicle provides a method to automatically design and tune the knowledge base adirect fuzzy controller. Furthermore in algorithms the number of fuzzy rules is automatically optimized. Any fuzzy controller can shows good performance for any system, but it's may not sufficient on unpredictable the changes of system's parameters or any load changes. But in this study for different scenarios shows that this method can construct suitable rule-base for a dc motor speed control system, takes approximate less $5 \mathrm{sec}$.

The results obtained in the study show that the fuzzy model reference learning system developed for DC motor speed control is applicable and has a high settling speed. The designed adaptive fuzzy controller has low settling time, system response of DC motor speed control has low steady-state error. The results show that the Fuzzy model reference learning controller algorithm can be used successfully for electrical vehicles (EVs) speed control applications. The important thing here is to obtain the reference model of the system whose fuzzy rules are to be obtained in a way that can best represent the system. Because, starting from the control of the model, the rule base table is obtained for the fuzzy control of the system. In this study, worked a novel fuzzy logic controller structure to learn rule-base and adjust to load and parameters changes. The applicability of the reference model-based fuzzy controls designed using the learning-based fuzzy inverse model for electric vehicle motor speed control has been examined and successful results have been obtained in the study. 
Bulut M., (2021)

\section{REFERENCES}

[1] W. Shephard and L.N. Hullay, "Power Electronics and Motor Control", Cambridge University Press, 1987

[2] A. Tashakori Abkenar, BLDC Motor Drive Controller for Electric Vehicles, Faculty of Science, Engineering and Technology Swinburne University of Technology, Doctor of Philosophy Thesis, May 2014.-

[3] Shahgholian, G., Maghsoodi, M., Mahdavian, M., Janghorbani, M., Azadeh, M., \& Farazpey, S. Analysis of speed control in DC motor drive by using fuzzy control based on model reference adaptive control. 13th Int. Conf. on Elec. Eng./Electronics, Computer, Telecommunications and Information Technology (ECTI-CON), 1-6. 2016.

[4] Layne J.R., Passino K.M., "Fuzzy Model Reference Learning Control for Cargo Ship Steering”, IEEE Control Systems Magazine, Vol. 13, No. 6, pp. 23-34, Dec. 1993.

[5] Layne J.R., Passino K.M., Yurkovich S., "Fuzzy Learning Control for Anti-Skid Braking Systems", IEEE Trans. on Control Systems Technology, Vol. 1, No. 2, pp. 122-129, June 1993.

[6]. S. Sheel, R. Chandkishor and O. Gupta, "Speed control of DC drives using MRAC technique," 2010 Int. Conf. on Mechanical and Electrical Technology, Singapore, 2010, pp. 135-139, doi: 10.1109/ICMET.2010.5598335.

[7]. Farahani, G., Rahmani, K. Speed Control of a Separately Excited DC Motor Using New Proposed Fuzzy Neural Algorithm Based on FOPID Controller. J Control Autom Electr Syst 30, 728-740, 2019. https://doi.org/10.1007/s40313019-00485-8

[8]. Christopher G. Moore, Indirect Adaptive Fuzzy Controllers, University of Sothampton, Phd Thesis, April 1992.

[9]. Rudolf Kruse, Detlef Nauck, Learning Methods For Fuzzy Systems, Proc. 3rd German GI-Workshop Neuro-Fuzzy Systems, Germany, Nov. 1995.

[10]. Delice E.K., A Fuzzy Multicriteria Model For Airline Companies Selection, Journal Of The Faculty Of Engineering And Architecture Of Gazi University, 31 (2), 263-276, 2016.

[11]. Kocakulak, T , Solmaz, H . Ön ve son iletimli paralel hibrit araçların bulanık mantık yöntemi ile kontrolü ve diğer güç sistemleri ile karşılaştırılması, Journal Of The Faculty Of Engineering \& Architecture Of Gazi University, 35 (4), 2269-2286, 2020. . DOI: 10.17341/gazimmfd.709101

[12] Moudgal V.G., Kwong W.A., Passino K.M., and Yurkovich S., "Fuzzy Learning Control for a Flexible-Link Robot", IEEE Transactions on Fuzzy Systems, Vol. 3, No. 2, pp. 199-210, May 1995.

[13] Kwong W.A., Passino K.M., "Dynamically Focused Fuzzy Learning Control”, IEEE Trans. on Systems, Man, and Cybernetics, Vol. 26, No. 1, pp. 53-74, Feb. 1996.

[14] Rudolf Kruse, Detlef Nauck, Learning Methods For Fuzzy Systems, Proc. $3^{\text {rd }}$ German GI-Workshop Neuro-Fuzzy Systems , Germany, Nov. 1995

[15]. Anwari, S. "Design of PI Controller for Angular Velocity Control of Brushed DC Motor plus Neuro Adaptive Control”, ReTII, 00, 2015. Available at: //journal.itny.ac.id/index.php/ReTII/article/view/58 (Accessed: 20October2020).

[16]. Xiaodi Li, and Shihua Li , Control for a PMSM Servo System Using Model Reference Adaptive Control and an Extended State Observer, Journal of Power Electronics, Volume 14 Issue 3, Pages.549-563, 2014.

[17] Yulan Qi, Separately Excited DC Motor for Electric Vehicle Controller Design, Proceedings of the 2016 Int. Conf. on Sensor Network and Computer Engineering, 332-336, July 2016. Doi:10.2991/icsnce-16.2016.65

[18] Enzo Illiano, Design of a Brushless Separately Excited Synchronous Motor,

https:/ethz.ch/content/dam/ethz/special-interest/mavt/energy-science-center-dam/events/frontiers-

presentations/140218_FiER_Illiano.pdf, [Access date: 09.10.2021]

[19]. Oltean, S.E. \& A brudean, M. \& Gligor, Adrian, MRAC and FMRLC for a plant with time varying parameters. Int. Conf. on Automation, Quality and Testing, Robotics. 1. 62-67, 2006. Doi: 10.1109/AQTR.2006.254498. 